\title{
Fumaquinone, a New Prenylated Naphthoquinone from Streptomyces fumanus
}

\author{
Romila D. Charan, ${ }^{\dagger}$ Gerhard Schlingmann, Valerie S. Bernan, Xidong Feng, Guy T. Carter
}

Received: January 5, 2005 / Accepted: March 16, 2005

(C) Japan Antibiotics Research Association

\begin{abstract}
A new prenylated naphthoquinone antibiotic, fumaquinone (5,7-dihydroxy-2-methoxy-3-methyl-6-(3methyl-but-2-enyl)[1,4]naphthoquinone) was isolated from cultures of Streptomyces fumanus (LL-F42248). Its chemical structure was determined primarily by NMR spectroscopy. Preliminary feeding experiments indicated the naphthoquinone is of polyketide origin, while the $O$-methyl and aromatic $C$-methyl groups are derived from methionine.
\end{abstract}

Keywords prenylated naphthoquinone, actinomycete, fumaquinone, antibiotic, stable isotope labeling

Although terpenoidal compounds are commonly produced by plants and fungi, only a very limited number of isoprene-derived moieties or structures have been reported as metabolites of actinomycetes [1]. Selected examples of prenylated naphthoquinones include naphterpin [2], naphthgeranines [3], furaquinocins [4, 5], marinone [6], neomarinone [7] and the napyradiomycin [8] family of compounds. These compounds generally exhibit antitumor, antibiotic or antioxidative activity [1].

During our studies of culture LL-F42248, Streptomyces fumanus, that is known for producing chlorinated antibiotics [9, 10], we isolated fumaquinone (1), a new prenylated naphthoquinone. Here, we report the isolation and structure elucidation of $\mathbf{1}$.

Characteristics of the producing organism and conditions

G. T. Carter (Corresponding author), R. D. Charan, G. Schlingmann, V. S. Bernan, X. Feng: Chemical and Screening Sciences, Wyeth Research, 401 N. Middletown Road, Pearl River, New York 10965, USA, E-mail: carterg@wyeth.com of its fermentation were described recently in a related publication [10]. As in the previous work, the polyamide resin together with the cell mass from 2 liter fermentation was extracted and purified by reversed-phase HPLC using acetonitrile/water. The fumaquinone rich fraction was then further purified by a second reversed-phase HPLC step using a linear gradient of $60 \sim 90 \% \mathrm{MeOH} / \mathrm{H}_{2} \mathrm{O}$ with $0.01 \%$ TFA over 10 minutes to give $\mathbf{1}(2.7 \mathrm{mg}, 15.1$ minutes) that was characterized by standard spectroscopic methods.

Fumaquinone was obtained as an orange solid and the molecular formula was established as $\mathrm{C}_{17} \mathrm{H}_{18} \mathrm{O}_{5}$ by highresolution Fourier transform ion cyclotron resonance (HRFT-ICR) mass spectrometry $\left(\mathrm{m} / \mathrm{z} 301.10835[\mathrm{M}-\mathrm{H}]^{1-}\right.$ calcd for $\mathrm{C}_{17} \mathrm{H}_{17} \mathrm{O}_{5} 301.10815$ ) which requires 9 degrees of unsaturation. Fumaquinone exhibited UV maxima at 224, 272, 308 and $428 \mathrm{~nm}$ (Fig. 2) that are characteristic for a 2oxy-[1,4]naphthoquinone (juglone) chromophore [2 5].

The NMR spectra provided further support for a substituted naphthoquinone moiety. The ${ }^{13} \mathrm{C}$ NMR (Table

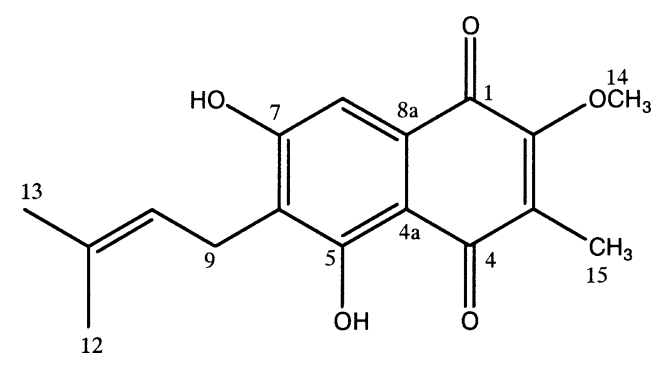

Fig. 1 Fumaquinone (1). ${ }^{\dagger}$ Present address: Albany Molecular Research, 21 Corporate
Circle, P. O. Box 15098, Albany, NY 12212-5098 


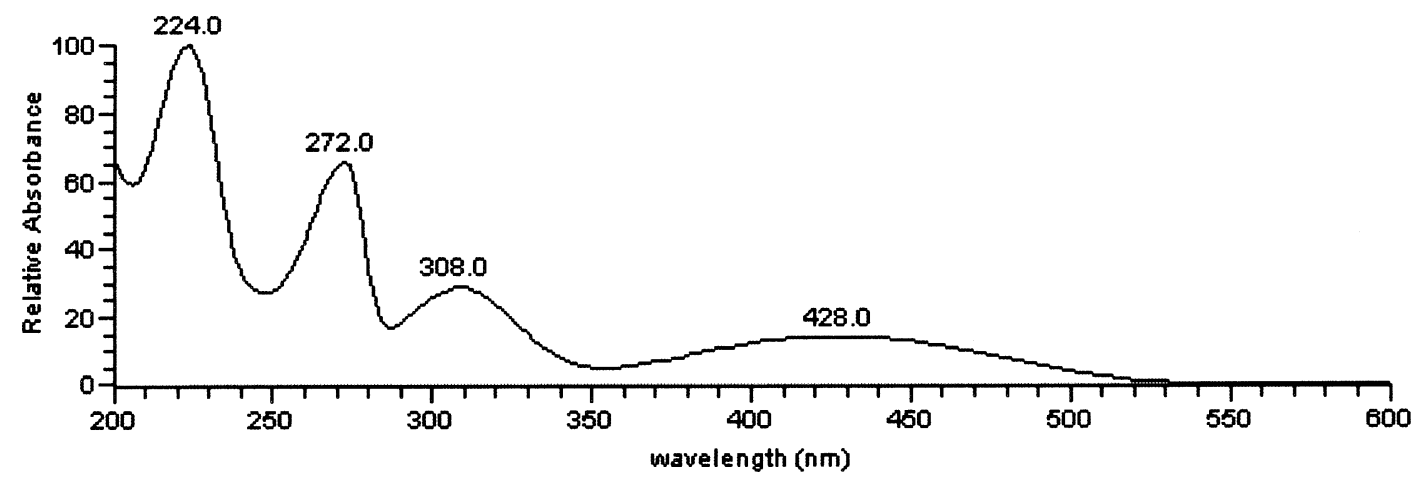

Fig. 2 UV spectrum of fumaquinone (1).

Table 1 NMR spectral data for 1 recorded in acetone- $d_{6}$ at $400 \mathrm{MHz}$

\begin{tabular}{|c|c|c|c|c|}
\hline pos. & $\delta_{\mathrm{C}}$ & $\delta_{\mathrm{H}}$ (mult., $J=\mathrm{Hz}$ ) & ${ }^{1} \mathrm{H}-{ }^{1} \mathrm{H} \operatorname{COSY}$ & $\mathrm{HMBC}$ \\
\hline 1 & 181.0 & - & - & - \\
\hline 2 & 158.9 & - & - & - \\
\hline 3 & 131.6 & - & - & - \\
\hline 4 & 191.0 & - & - & - \\
\hline $4 a$ & 109.1 & - & - & - \\
\hline 5 & $162.2^{\mathrm{a}}$ & - & - & - \\
\hline 6 & 122.3 & - & - & - \\
\hline 7 & $161.9^{a}$ & - & - & - \\
\hline 8 & 108.2 & 7.13 (s) & - & C-1, C-4a, C-6, C-7, C-8a \\
\hline $8 a$ & 131.7 & - & - & - \\
\hline 9 & 22.7 & $3.39(d, 7.4)$ & $\mathrm{H}-10$ & C-5, C-6, C-7, C-10, C-11 \\
\hline 10 & 122.0 & $5.23(t, 7.2)$ & $\mathrm{H}-9, \mathrm{H}-12, \mathrm{H}-13$ & C-9, C-12, C-13 \\
\hline 11 & 132.7 & - & - & - \\
\hline 12 & 18.0 & 1.78 (br s) & $\mathrm{H}-13$ & C-10, C-11, C-13 \\
\hline 13 & 25.9 & 1.65 (br s) & $\mathrm{H}-12$ & $\mathrm{C}-10, \mathrm{C}-11, \mathrm{C}-12$ \\
\hline 14 & 61.3 & $4.07(\mathrm{~s})$ & - & C-2 \\
\hline 15 & 8.8 & 1.99 (s) & - & C-2, C-3, C-4 \\
\hline $5-\mathrm{OH}$ & - & 12.80 (s) & - & C-4a, C-5, C-6 \\
\hline $7-\mathrm{OH}$ & - & 9.78 (br s) & - & - \\
\hline
\end{tabular}



1) of 1 in acetone- $d_{6}$ displayed resonances for two carbonyls at $\delta 191.1$ and 181.0 and ten olefinic and/or aromatic carbons between $\delta_{\mathrm{C}} 108.2$ and $\delta_{\mathrm{C}} 162.2$. The ${ }^{1} \mathrm{H}$ NMR spectrum in acetone- $d_{6}$ showed nine resonances due to one aromatic proton $\left(\delta_{\mathrm{H}} 7.13\right)$, one methoxy $\left(\delta_{\mathrm{H}} 4.07\right)$, three methyls $\left(\delta_{\mathrm{H}} 1.99,1.78,1.65\right)$, one methylene $\left(\delta_{\mathrm{H}}\right.$ 3.39) and one methine $\left(\delta_{\mathrm{H}} 5.23\right)$. The HSQC data of 1 indicated that two hydrogen atoms were located on heteroatoms and were readily recognized by their chemical shifts as phenolic hydroxyl protons $\left[5-\mathrm{OH}\left(\delta_{\mathrm{H}} 12.80\right)\right.$, and $\left.7-\mathrm{OH}\left(\delta_{\mathrm{H}} 9.78\right)\right]$.

The ${ }^{13} \mathrm{C}$ resonances at $\delta_{\mathrm{C}} 191.1$ and 181.0 and eight other olefinic carbon resonances were assigned to the naphtho1,4-quinone moiety based on the following correlations. A methine proton resonance at $\delta_{\mathrm{H}} 7.13$ was assigned to $\mathrm{H}-8$ on the basis of strong HMBCs from H-8 to C-1 $\left(\delta_{\mathrm{C}} 181.0\right)$, C-4a $\left(\delta_{\mathrm{C}} 109.1\right), \mathrm{C}-6\left(\delta_{\mathrm{C}} 122.3\right), \mathrm{C}-7\left(\delta_{\mathrm{C}} 161.9\right)$ and C-8a $\left(\delta_{\mathrm{C}} 131.7\right)$. Further, HMBCs from the methoxy protons at $\delta_{\mathrm{H}} 4.07$ to the olefinic carbon $\mathrm{C}-2\left(\delta_{\mathrm{C}} 158.9\right)$ and from the allylic methyl at $\delta_{\mathrm{H}} 1.99$ to $\mathrm{C}-2, \mathrm{C}-3\left(\delta_{\mathrm{C}} 131.6\right)$ and C-4 were indicative of a methoxy and a methyl substituent on the naphthoquinone moiety. HMBC correlations from the hydroxyl proton at $\delta_{\mathrm{H}} 12.80$ to C-4a, C-5 $\left(\delta_{\mathrm{C}} 162.2\right)$ and C6 secured its position at C-5. Although the relatively broad 
resonance of a hydroxyl proton at $\delta_{\mathrm{H}} 9.78$ did not show any HMBCs, it was assigned to the C-7 hydroxyl group by exclusion which completed the assessment of the 5,7dihydroxy-2-methoxy-3-methyl-[1,4]-naphthoquinone moiety.

The remaining resonances in ${ }^{1} \mathrm{H}$ and ${ }^{13} \mathrm{C}$ NMR spectra, correlated by ${ }^{1} \mathrm{H}-{ }^{1} \mathrm{H}$ COSY, HSQC and $\mathrm{HMBC}$ data, readily identified the dimethyl allyl side chain as the remaining substituent. COSY correlations from $\mathrm{H}-9$ at $\delta_{\mathrm{H}} 3.39$ to $\mathrm{H}-10$ at $\delta_{\mathrm{H}} 5.23$ and allylic coupling between $\mathrm{H}-10$ and $\mathrm{H}-12\left(\delta_{\mathrm{H}} 1.78\right)$ as well as between $\mathrm{H}-10$ and $\mathrm{H}-13$ $\left(\delta_{\mathrm{H}} 1.65\right)$ established the spin system from $\mathrm{H}-9$ to $\mathrm{H}-13$. The presence of the dimethyl allyl group was further corroborated by HMBC correlations from $\mathrm{H}-9$ to $\mathrm{C}-10$ $\left(\delta_{\mathrm{C}} 122.0\right)$ and $\mathrm{C}-11\left(\delta_{\mathrm{C}} 132.7\right)$ and from $\mathrm{H}-10$ to $\mathrm{C}-9$ $\left(\delta_{\mathrm{C}} 22.7\right), \mathrm{C}-12\left(\delta_{\mathrm{C}} 18.0\right)$ and $\mathrm{C}-13\left(\delta_{\mathrm{C}} 25.9\right)$. Mutual correlations between $\mathrm{H}-12$ and $\mathrm{C}-13$ and $\mathrm{H}-13$ and $\mathrm{C}-12$ further supported the assignment of the dimethyl allyl side chain. The dimethyl allyl side chain was placed on the naphthoquinone moiety at C-6 on the basis of HMBC correlations from $\mathrm{H}-9$ to $\mathrm{C}-5\left(\delta_{\mathrm{C}} 162.2\right), \mathrm{C}-6\left(\delta_{\mathrm{C}} 122.3\right)$ and $\mathrm{C}-7\left(\delta_{\mathrm{C}} 161.9\right)$. The structure of 1 was thus shown to be 5,7-dihydroxy-2-methoxy-3-methyl-6-(3-methyl-but-2enyl) $[1,4]$ naphthoquinone.

Feeding experiments using L- $\left[\right.$ methyl $\left.-{ }^{13} \mathrm{C}\right]$ methionine indicated that the methoxy $(\mathrm{C}-14)$ and the aromatic methyl (C-15) groups were derived from methionine with isotopic enrichment of $>85 \%$ for each carbon. Preliminary work with $\left[1,2-{ }^{13} \mathrm{C}_{2}\right]$ sodium acetate indicated that the biosynthesis of the juglone moiety follows the polyketide pathway, a finding similar to that of the furaquinocins [11] which share the juglone moiety.

Fumaquinone is the first prenylated naphthoquinone isolated from $S$. fumanus. It showed antimicrobial activity against selected Gram-positive bacteria with MIC of about $64 \mu \mathrm{g} / \mathrm{ml}$.

\section{Experimental}

\section{General Experimental Procedures}

All 1D and 2D NMR spectra were recorded on a Bruker Avance DPX-400 spectrometer at 400 and $100 \mathrm{MHz}$ for ${ }^{1} \mathrm{H}$ and ${ }^{13} \mathrm{C}$, respectively, using a $3 \mathrm{~mm}$ broadband detect probe. Proton detected heteronuclear correlations were measured using HSQC (optimized for ${ }^{1} J_{\mathrm{C}-\mathrm{H}}=140 \mathrm{~Hz}$ ) and $\mathrm{HMBC}$ (optimized for ${ }^{\mathrm{n}} J_{\mathrm{C}-\mathrm{H}}=8.3 \mathrm{~Hz}$ ) pulse sequences. UV data were obtained on HP1100 HPLC system equipped with DAD. High resolution mass spectra (HRMS) were obtained using a Bruker (Billerica, MA) APEXII FTICR mass spectrometer equipped with an actively shielded 7.1 Tesla superconducting magnet (Magnex Scientific Ltd., UK), an external Bruker APOLLO ESI source, and a Synrad 50W $\mathrm{CO}_{2} \mathrm{CW}$ laser. The molecular ion at $\mathrm{m} / \mathrm{z} 301$ was isolated using correlated sweep and then dissociated using Infrared Multi-Photon Dissociation (IRMPD). All HPLC solvents were EM Omnisolv quality and used without further purification.

\section{Isolation and Purification Procedures}

The harvested fermentation broth (2 liters) was centrifuged at $4000 \mathrm{rpm}$ for 20 minutes and the polyamide resin together with the cell mass was extracted with acetone $(2 \times 200 \mathrm{ml})$. The combined acetone extract was concentrated in vacuo and the aqueous suspension extracted with ethyl acetate $(3 \times 60 \mathrm{ml})$. The ethyl acetate extract $(1.5 \mathrm{~g})$ was purified by reversed-phase HPLC (YMC ODS-A column, $20 \times 250 \mathrm{~mm}, 5 \mu \mathrm{m})$ using a gradient of $40 \sim 90 \%$ acetonitrile/water containing $0.05 \%$ TFA in water over 40 minutes at a flow rate of $7 \mathrm{ml} /$ minute. Final purification of the fumaquinone rich fraction $(10 \mathrm{mg})$ was achieved by reversed-phase HPLC (YMC ODS-A column, $10 \times 250 \mathrm{~mm}, 5 \mu \mathrm{m}$ ) using a gradient of $60 \sim 90 \%$ methanol/water with $0.02 \%$ TFA in water over 10 minutes and maintaining for 5 minutes at a flow rate of $4 \mathrm{ml} /$ minute to give fumaquinone (1, 2.7 $\mathrm{mg}, 15.1$ minutes) as an orange solid.

\section{L-[methyl $\left.-{ }^{13} \mathrm{C}\right]$ methionine Feeding Experiment}

A solution of $\mathrm{L}-\left[\right.$ methyl $\left.-{ }^{13} \mathrm{C}\right]$ methionine at a final concentration of $10 \mathrm{mM}$ was added to the production medium described previously [10]. The fermentation was harvested at five days and processed as described above.

\section{$\left[1,2-{ }^{13} \mathbf{C}_{2}\right]$ sodium Acetate Feeding Experiment}

$\left[1,2-{ }^{13} \mathrm{C}_{2}\right]$ sodium acetate was added to the production medium described previously [10] at a final concentration of $10 \mathrm{mM}$. The fermentation was harvested at five days and processed as described above.

Acknowledgements We thank D. Arias and M. Singh of Wyeth's Natural Products Discovery Department for assay support.

\section{References}

1. Kuzuyama T, Seto H. Diversity of the biosynthesis of the isoprene units. Nat Prod Rep 20: 171-183 (2003)

2. Shin-Ya K, Imai S, Furihata K, Hayakawa Y, Kato Y, Vanduyne GD, Clardy J, Seto H. Isolation and structural elucidation of an antioxidative agent, naphterpin. J Antibiot 43: 444-447 (1990) 
3. Wessels P, Gohrt A, Zeeck A, Drautz H, Zahner H. Metabolic products of microorganisms, 260. Naphthgeranines, new naphthoquinone antibiotics from Streptomyces sp. J Antibiot 44: 1013-1018 (1991)

4. Funayama S, Ishibashi M, Anraku Y, Komiyama K, Ōmura, S. Structures of novel antibiotics, furaquinocins A and B. Tetrahedron Lett 30: 7427-7430 (1989)

5. Ishibashi M, Funayama S, Anraku Y, Komiyama K, Ōmura S. Novel antibiotics, furaquinocins C, D, E, F, G and H. J Antibiot 44: 390-395 (1991)

6. Pathirana C, Jensen PR, Fenical W. Marinone and debromomarinone: Antibiotic sesquiterpenoid naphthoquinones of a new structure class from a marine bacterium. Tetrahedron Lett 33: 7663-7666 (1992)

7. Kalaitzis JA, Hamano Y, Nilsen G, Moore BS. Biosynthesis and structural revision of neomarinone. Org Lett 5: 4449-4452 (2003)
8. Fukuda DS, Mynderse JS, Baker PJ, Berry DM, Boeck LD, Yao RC, Mertz FP, Nakatsukasa WM, Mab J, Ott J, Counter FT, Ensminger PW, Allen NE, Alborn WE, Hobbs JN. A80915, A new antibiotic complex produced by Streptomyces aculeolatus. Discovery, taxonomy, fermentation, isolation, characterization, and antibacterial evaluation. J Antibiot 43: 623-633 (1990)

9. Carter GT, Nietsche JA, Goodman JJ, Torrey MJ, Dunne TS, Borders DB, Testa RT. LL-F42248 $\alpha$, a novel chlorinated pyrrole antibiotic. J Antibiot 40: 233-236 (1987)

10. Charan RD, Schlingmann G, Bernan VS, Feng X, Carter GT. Additional pyrrolomycins from cultures of Streptomyces fumanus. J Nat Prod 68: 277-279 (2005)

11. Funayama $\mathrm{S}$, Ishibashi $\mathrm{M}$, Komiyama $\mathrm{K}$, Ōmura $\mathrm{S}$. Biosynthesis of furaquinocins A and B. J Org Chem 55: 1132-1133 (1990) 